\title{
Isolation and Characteristics of a Microbial Consortium for Effectively Degrading Phenanthrene
}

\author{
Wang Jing, Xu Hongke and Guo Shaohui \\ (School of Chemical Science \& Engineering, China University of Petroleum, Beijing 102249, China)
}

\begin{abstract}
A microbial consortium (named W4) capable of aerobic biodegradation of solid phenanthrene as the sole source of carbon and energy was isolated by selective enrichment from petroleum-contaminated soil in the Henan oilfield, China. The strains of the consortium were identified as Sphingomonas cloacae, Rhizobium sp., Pseudomonas aeruginosa and Achromobacter xylosoxidans respectively by means of genetic methods. The major metabolites of phenanthrene were analyzed by gas chromatography-mass spectrometry (GC-MS). The biodegradation percentage of solid phenanthrene at $200 \mathrm{mg} / \mathrm{L}$ in liquid medium after 7 days of growth was greater than $99 \%$. The degradation of phenanthrene was compared between individual predominant strains and the microbial consortium in different treatment processes. The microbial consortium showed a significant improvement of phenanthrene degradation rates in either static or shaking culture. The degradation percentage of phenanthrene by the consortium W4 decreased to some degree when $\mathrm{C} 16$ coexisted, however it was hardly affected by C30. Furthermore, the ability of consortium W4 to remediate oil sludge from the Dagang oil refinery was studied by composting; and it was found that the consortium W4 could obviously remove polycyclic aromatic hydrocarbons (PAHs) and paraffinic hydrocarbons. All the results indicated that the microbial consortium W4 had a promising application in bioremediation of oil-contaminated environments and could be potentially used in microbial enhanced oil recovery (MEOR).
\end{abstract}

Key words: Phenanthrene, consortium, biodegradation, bioremediation

\section{Introduction}

Polycyclic aromatic hydrocarbons (PAHs) are a ubiquitous class of hydrophobic organic compounds consisting of two or more fused benzene rings in linear, angular, or cluster arrangements. PAHs are found in the environment after the disposal of coal processing wastes, oil sludge, asphalt, creosote, and other wood preservative wastes, and they exist within the ecosystem for years owing to their low water solubility and adsorption to solid particles (Habe and Omori, 2003). Due to the bioaccumulation tendency of PAHs in food chain, the decontamination of PAH-polluted sites is urgent (Hughes, et al., 1997; Meudec, et al., 2006; Boffetta, et al., 1997). Tang, et al. (2005) reported that the mean concentration of total PAHs (based on 16 USEPA priority PAHs) in urban soil samples in Beijing was around $3917 \mathrm{ng} \cdot \mathrm{g}^{-1}$ dry weight, ranging from 219 $\mathrm{ng} \cdot \mathrm{g}^{-1}$ to $27,825 \mathrm{ng} \cdot \mathrm{g}^{-1}$.

Microbial degradation is believed to be one of the major processes to clean up PAH-contaminated environments, previous studies have reported that indigenous microbial communities had a considerable potential to remedy oil-contaminated soil and to remove phenanthrene from aqueous solution (Yu, et al., 2005). The efficiency of PAH degradation in medium mixed with other carbon sources or in oil sludge was different from that in liquid medium as sole carbon source. There would be synergistic interaction or inhibition between
PAH and other carbon sources (Van Ha, et al., 2003). The advantages of employing mixed cultures as opposed to pure cultures in bioremediation have also been widely demonstrated (He, et al., 2004; Ghazali, et al., 2004). It could be attributed to the effect of synergistic interactions among members of the association (Ghazali, et al., 2004). The present study therefore aims to: 1) Examine the capability of a bacterial consortium isolated from oil-contaminated soil to degrade solid phenanthrene as a model PAH in liquid medium and analyze the metabolites; 2) Investigate the degradation rate of solid phenanthrene when alkane (C16 or C30) existed; 3) Study the effect of the enriched bacterial consortium on the bioremediation of oil sludge.

\section{Materials and methods}

\subsection{Enrichment and isolation of the phenanthrene- degrading microbial consortium}

Mineral salt medium (MSM) was used as culture medium and, phenanthrene (Phe) (purity 97.0\%), purchased from Beijing Chemicals, China, was used as the model PAH compound. MSM had the following composition (in $\mathrm{g} / \mathrm{L}$ distilled water): $\mathrm{K}_{2} \mathrm{HPO}_{4} \cdot 3 \mathrm{H}_{2} \mathrm{O}, 3 ; \mathrm{KH}_{2} \mathrm{PO}_{4}, 3 ; \mathrm{NaCl}, 0.5 ; \mathrm{NH}_{4} \mathrm{Cl}, 1$; $\mathrm{MgSO}_{4} \cdot 7 \mathrm{H}_{2} \mathrm{O}, 0.5 ; \mathrm{CaCl}_{2}$ (trace); $\mathrm{FeCl}_{3}$ (trace). The medium $\mathrm{pH}$ was around 6.65. Phe was added directly into MSM in solid state. A quantity of fresh oil-contaminated soil was added into $50 \mathrm{~mL}$ 
sterilized MSM containing $200 \mathrm{mg} / \mathrm{L}$ solid Phe in conical flask. Although this concentration was much higher than the real contamination level in environment, it was common to use an elevated concentration for enrichment to ensure that the PAH degraders were selected (Yu, et al., 2005). The flask was shaken in an orbital shaker $(120 \mathrm{rpm})$ at $37{ }^{\circ} \mathrm{C}$ for one week for microbial enrichment, then the aliquot of $2 \mathrm{~mL}$ enriched culture was inoculated into another $100-\mathrm{mL}$ conical flask containing $50 \mathrm{~mL}$ fresh MSM with the same amount of solid Phe for the second enrichment.

After four consecutive enrichments, the cultures with a series of concentration gradient were inoculated on the MSM agar plates containing a thin layer of Phe respectively to get the enriched consortium and the separated Phe-degrading microorganism with a clearing zone around the inoculated region. The isolation and purification of the bacterial consortium were carried out on nutrient agar plates by conventional spread plate techniques.

\subsection{Biodegradation of phenanthrene in liquid medium}

To prepare the microbial consortium, loopfuls of each isolated species stored on nutrient agar slant were inoculated together in $50 \mathrm{~mL}$ MSM containing 200 $\mathrm{mg} / \mathrm{L}$ solid Phe in a conical flask. The flask was shaken in an orbital shaker $(120 \mathrm{rpm})$ at $37^{\circ} \mathrm{C}$ in the dark for 4 days to reach the phase of exponential growth. To start the biodegradation experiment, $2 \mathrm{~mL}$ aliquot of the above culture was added aseptically to $50 \mathrm{~mL}$ new MSM containing $200 \mathrm{mg} / \mathrm{L}$ solid Phe to give an initial optical density of around 0.01-0.015. The flask was shaken in the same way as mentioned above. A control flask with MSM containing $200 \mathrm{mg} / \mathrm{L}$ solid Phe (but no bacterial consortium) was used to check for abiotic losses of Phe during experiments. At the end of 7 days, the residual Phe and metabolites of both the bacterial consortium and the control flask were determined by GC-MS. For degradation of solid Phe mixed with $\mathrm{C} 16$ or $\mathrm{C} 30$, the procedures were the same as those in the degradation of solid Phe as sole carbon source in liquid medium, except for adding saturate liquid C16 to a concentration of $3 \mathrm{~mL} / \mathrm{L}$ or solid $\mathrm{C} 30$ to a concentration of $200 \mathrm{mg} / \mathrm{L}$ respectively. The biodegradation percentage was calculated as follows: (Residual Phe concentration in the control flask - Residual Phe concentration in the degradation flask)/(Residual Phe concentration in the control flask) $\times 100 \%(\mathrm{Yu}$, et al., 2005).

\subsection{Extraction of phenanthrene and its major metabolites}

To extract Phe and its major metabolites, $50 \mathrm{~mL}$ of cell suspension was harvested after 7 days degradation, and acidified to $\mathrm{pH} 2.0$ with $1 \mathrm{M} \mathrm{HCl}$; extracts were taken for three times, first with equal volumes of dichloromethane, then with half volumes of ethyl acetate for another two times. The dichloromethane and ethyl acetate solvents were evaporated in water bath at $40{ }^{\circ} \mathrm{C}$ and $80{ }^{\circ} \mathrm{C}$ respectively. Then both residues were dissolved in dichloromethane again to be mixed together. The mixed extracts were finally reduced to less than $1 \mathrm{~mL}$ for GC-MS analysis (Xu, et al., 2004; Samamta, et al., 1999; Kim, et al., 2005). For the control flask, the procedures were conducted in the same way but without the concentrating process. A series of solutions with different concentrations were used to make external standard curves. GC-MS analysis was performed with Thermo-Finngan Trace DSQ and completed by the Center of Analytical Services of State Key Laboratory of Heavy Oil Processing, China University of Petroleum (Beijing). Gas Chromatography was equipped with a quartz capillary $(30 \mathrm{~m} \times 0.25 \mathrm{~mm} \times 0.25 \mu \mathrm{m})$. Helium was used as carrier gas (16 spi). The injector temperature was $300{ }^{\circ} \mathrm{C}$. The initial oven temperature was $80^{\circ} \mathrm{C}$ and was held for 1 min and then increased to $300{ }^{\circ} \mathrm{C}$ at $8{ }^{\circ} \mathrm{C} / \mathrm{min}$ and held for $5 \mathrm{~min}$; injection was performed in split mode $(60: 1)$ at a constant temperature. Mass spectrometry was conducted under the following conditions: scan time of $0.8 \mathrm{~s}$ and a mass-range of 35-400 amu; EI (electron impact) of $70 \mathrm{eV}$, and emission current of $200 \mu \mathrm{A}$.

\subsection{Identification of microbial consortium}

The isolated species were first identified by color and morphology of individual colonies, then by traditional biochemical tests (The Group of Bacteriology Classification of the Institute of Microbiology, Chinese Academy of Science, 1978). After that the purified bacterium was identified by the sequence of $16 \mathrm{~S}$ rDNA in variable regions after amplification of the gene by PCR using the universal set of primers 960f-GC1 [5'-(GC clamp 1)-AAC GCG AAG AAC CTT AC-3'] and 1392r (5'-ACG GGC GGT GTG TAC A-3'), the sequence of GC clamp 1 is: 5'-CGC CCG GGG CGC GCC CCG GGC GGG GCG GGG GCA CGG GGG G-3'. The amplification fragments are V6-V8 regions of 16S rDNA (Liu and Ritalahti, 1996). The PCR reaction mixture (final volume $=25 \mu \mathrm{L}$ ) was prepared in a single tube as follows: $1 \times$ PCR buffer, $2 \mathrm{mM} \mathrm{MgCl} 2,0.1 \mathrm{mM}$ dNTPs, $0.1 \mu \mathrm{M}$ of each primer, about $30 \mathrm{ng}$ genomic DNA from isolates, 
and $0.625 \mathrm{U}$ Taq DNA polymerase. Thermal cycling was performed in FTGENE5D DNA Engine (Techgene Ltd.) with a profile consisting of 35 cycles at $94{ }^{\circ} \mathrm{C}$ for 1 min, $54{ }^{\circ} \mathrm{C}$ for $1 \mathrm{~min}$ and $72{ }^{\circ} \mathrm{C}$ for $1 \mathrm{~min}$. Purification and DNA sequencing of PCR products (about $432 \mathrm{bp}$ ) were completed by Beijing U-biogene Co., Ltd. (Beijing, China). Database search with the determined 16S rDNA sequence was conducted by using the BLASTN program from National Center of Biotechnology Information (NCBI).

\subsection{Oil sludge degradation}

Oil sludge was provided by the oil refinery in the Dagang oilfield, China. Seventy grams of non-sterilized oil sludge was mixed thoroughly with $40 \mathrm{~g}$ of bulking agent of wood shaving, and then placed in a paper cup (height $85 \mathrm{~mm}$, diameter $52 \mathrm{~mm}$ and $72 \mathrm{~mm}$ respectively) to form a composting pile. Finally $20 \mathrm{~mL}$ microbial consortium isolated previously was inoculated in the pile. Control experiment was conducted under the same conditions without inoculation but instead with the addition of $20 \mathrm{~mL}$ of water. A carbon-rich bulking agent (wood shaving) was added to improve oxygen diffusion and create suitable aerobic conditions within the piles. The piles were watered and turned periodically to keep suitable level of humidity. The composting experiment was conducted from March 28th to May 28th, 2006, at an average temperature of about $20{ }^{\circ} \mathrm{C}$. After two months, total petroleum hydrocarbons in the composting pile and in the initial oil sludge were extracted with dichloromethane according to Wei, et al (2005) for GC-MS analysis to compare the variation of components of petroleum hydrocarbons.

\section{Results and discussion}

\subsection{Isolation of phenanthrene-degrading microbial consortium}

A microbial consortium (named W4) capable of degrading Phe was isolated after 4 weeks of selective enrichment by repeatedly subcultures. W4 consisted of 4 bacterial strains: W4-1, W4-2, W4-3 and W4-4. W4 was able to grow on and degrade solid Phe as the sole source of carbon and energy in liquid medium and, after 7 days growth, solid Phe almost disappeared accompanied by the production of brown metabolites. The formation of brown metabolites also showed the degradation of Phe by microbial consortium (Zhang and Hiroshi, 2003). Except W4-2, W4-3 and W4-4, there were distinct clearing zones around the lawn of W4 and the colony of W4-1 (Fig. 1) after $36 \mathrm{~h}$ of inoculation. This might be due to that W4-1 was able to degrade Phe individually and W4 degraded Phe more effectively through the synergetic reaction of four single strains.

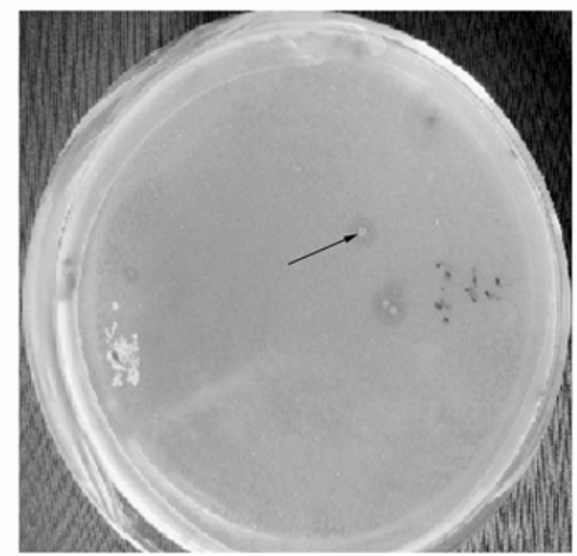

Fig. 1 Clearing zone (W4-1); arrow points

\subsection{Biodegradation of phenanthrene and analysis of extracellular metabolites}

The total abiotic loss of Phe during the degradation experiment and extraction process was $1.9 \%$. The biodegradation percentage of Phe after 7 days of microbial consortium growth was greater than $99 \%$. When the extracts were subjected to GC-MS analysis (Fig. 2; Table 1), the major metabolites were identified as o-phthalates whose retention time were $17.19 \mathrm{~min}$, $18.43 \mathrm{~min}$ and $25.07 \mathrm{~min}$ respectively. It indicated that W4 might degrade Phe via o-phthalic acid to $\mathrm{CO}_{2}$ and $\mathrm{H}_{2} \mathrm{O}$ (Wang, et al., 2006). Further investigation should be aimed at the toxicity of the intermediates; whether the intermediates produced by incomplete degradation have the potential to form the basis for a purposeful biosynthesis of compounds that are important chemicals and antioxidants in biomedicine and in the cosmetics industry (Baboshin, et al., 2005).

\subsection{Identification of the microbial consortium W4}

W4-1, W4-2, W4-3 and W4-4 were identified as Sphingomonas cloacae, Rhizobium sp., Pseudomonas aeruginosa and Achromobacter xylosoxidans, respectively, on the basis of $16 \mathrm{~S}$ rDNA sequence in combination with biochemical tests and morphology (Table 2; Table 3; Fig 3). As a matter of fact, strains belonging to Sphingomonas sp. and Pseudomonas sp. are frequently isolated as PAHs degraders $(\mathrm{Ma}$, et al., 2005). 


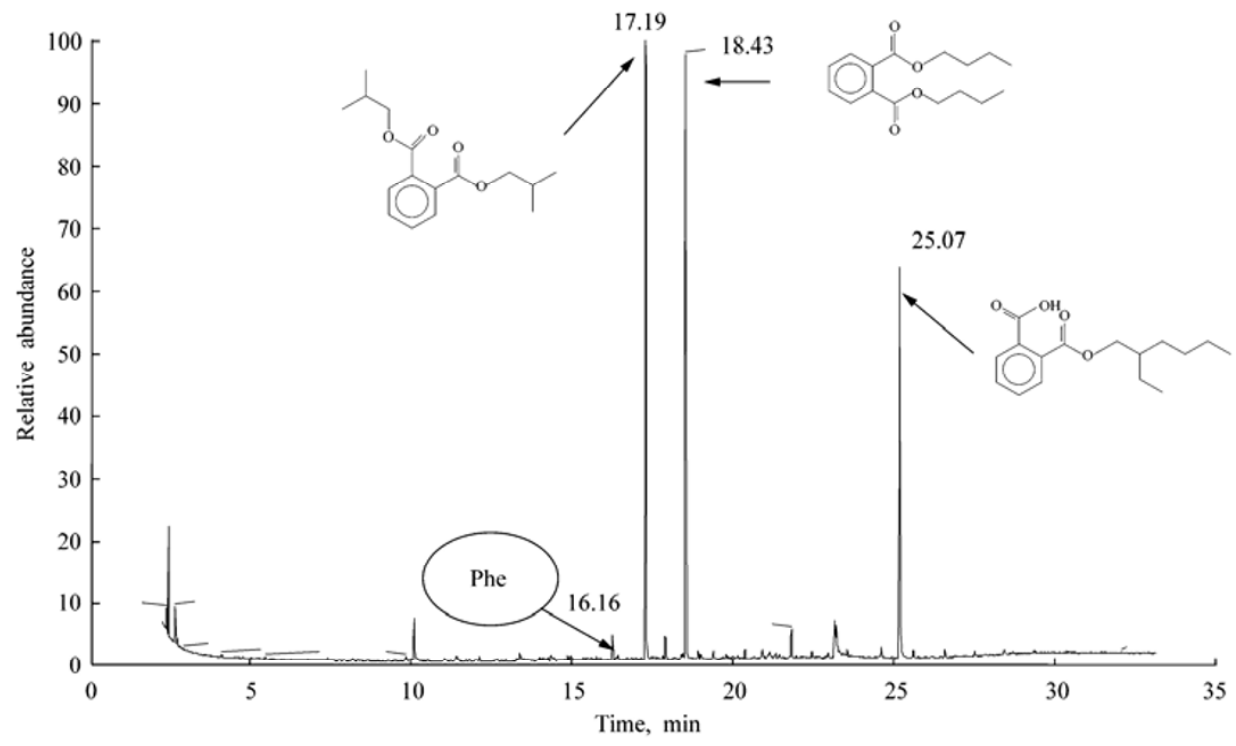

Fig. 2 GC-MS analysis of extra cellular intermediates of phenanthrene degradation by W4

Table 1 GC-MS of major metabolites formed from the degradation of phenanthrene by W4

\begin{tabular}{|c|c|c|c|c|}
\hline Compound & Retention time, min & \multicolumn{3}{|c|}{ Major characteristic peaks in the mass spectrum, $\mathrm{m} / \mathrm{z}(\%)$} \\
\hline & 16.16 & \multicolumn{3}{|c|}{$\mathrm{M}^{+} 179(14), 178(100), 176(17), 89(8)$} \\
\hline & 17.19 & & \multicolumn{2}{|c|}{$\mathrm{M}^{+} 223(7), 150(9), 149(100), 57(13)$} \\
\hline & 18.43 & & \multicolumn{2}{|c|}{$\mathrm{M}^{+} 223(5), 205(5), 150(9), 149(100)$} \\
\hline & 25.07 & & \multicolumn{2}{|c|}{$\mathrm{M}^{+} 167(40), 149(100), 71(17), 57$ (21) } \\
\hline \multicolumn{5}{|c|}{ Table 2 Some selected biochemical tests } \\
\hline Characteristic & W4-1 & W4-2 & W4-3 & W4-4 \\
\hline Pigment & $+($ Yellow $)$ & - & $+($ Green $)$ & - \\
\hline Gram reaction & - & - & - & - \\
\hline Catalase & \pm & + & + & + \\
\hline Oxidase & + & + & + & + \\
\hline \multicolumn{5}{|l|}{ Acid production from } \\
\hline Glucose of open & + & + & + & - \\
\hline Glucose of closed & + & + & - & - \\
\hline Starch hydrolysis & - & - & - & - \\
\hline Nitrate reduction & - & + & + & + \\
\hline Urease & - & + & + & - \\
\hline Citrate growth & - & + & + & + \\
\hline Anaerobic growth & + & + & + & + \\
\hline
\end{tabular}

Notes: +, positive; -, negative; \pm , weakly positive 
Table 3 List of sequenced microorganisms and the corresponding species in Genbank

\begin{tabular}{|c|c|c|c|}
\hline Microorganism & $\begin{array}{l}\text { Length of } 16 \mathrm{~S} \text { rDNA } \\
\text { V6-V8 fragments, bp }\end{array}$ & $\begin{array}{c}\text { Source of the most } \\
\text { similar GenBank sequence }\end{array}$ & $\begin{array}{l}\text { Alignment, } \\
\text { \%similarity }\end{array}$ \\
\hline \multirow[t]{2}{*}{ W4-1 } & 441 & AY151393 & $397 / 398,99 \%$ \\
\hline & & Sphingomonas cloacae & \\
\hline \multirow[t]{2}{*}{ W4-2 } & 436 & AY631059 & $390 / 402,97 \%$ \\
\hline & & Rhizobium sp. TKW1 & \\
\hline \multirow[t]{2}{*}{ W4-3 } & 545 & AE004091 & $395 / 396,99 \%$ \\
\hline & & Pseudomonas aeruginosa & \\
\hline \multirow[t]{2}{*}{ W4-4 } & 432 & AY 189752 & $392 / 393,99 \%$ \\
\hline & & Achromobacter xylosoxidants & \\
\hline
\end{tabular}
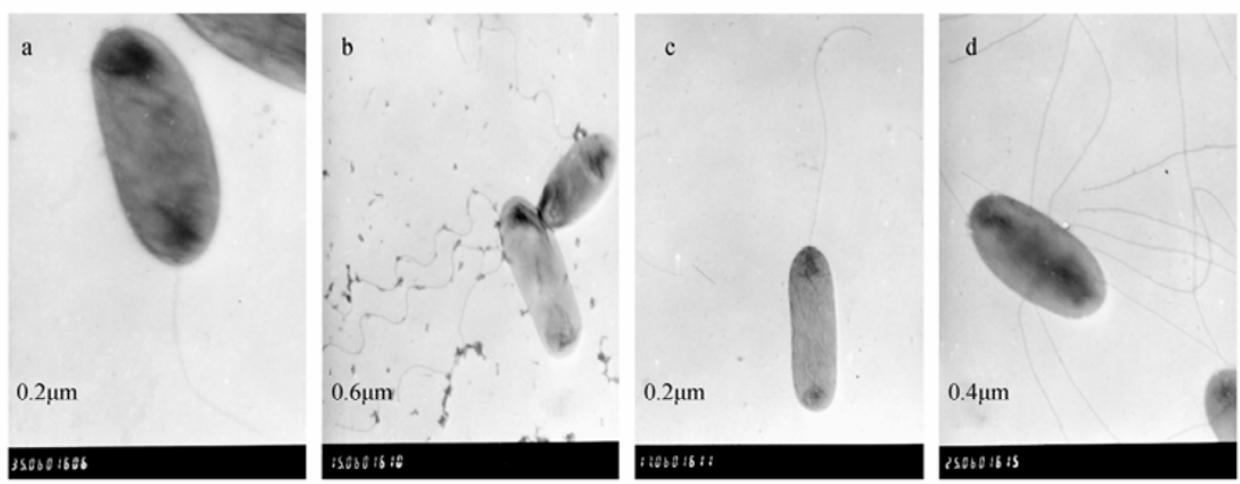

Fig. 3 Transmission electron micrograph of constituting strains of consortium W4

$$
\begin{aligned}
& \text { a: W4-1 Sphingomonas sp.; } \\
& \text { c: W4-3 Pseudomonas aeruginosa; }
\end{aligned}
$$

\subsection{Growth of the microbial consortium and its} constituting strains

Table 4 shows the growth of different microorganisms on Phe as the sole source of carbon and energy under different conditions. Bacterium strain W4-1 was able to utilize Phe individually, whereas W4-2, W4-3 and W4-4 did not show utilization of Phe separately. The predominance of W4-1 in the degrading

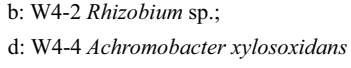

consortium suggested that this strain might have a prevalent role in the process. On the other hand, compared with single W4-1, the microbial consortium W4 showed a significant improvement on phenanthrene degradation rate in static or shaking culture, which might be attributed to the synergetic reaction of single strains. The exact degradation pathway and the role of each strain in the consortium are still unknown and are being investigated.

\begin{tabular}{|c|c|c|c|c|c|}
\hline Feature & W4 & W4-1 & W4-2 & W4-3 & W4-4 \\
\hline Growth in liquid MSM (shaking) & ++ & + & - & \pm & \pm \\
\hline Residual Phe after 7 days (liquid, shaking) & - & + & ++ & ++ & ++ \\
\hline Growth in liquid MSM (static) & ++ & \pm & - & - & - \\
\hline Residual Phe after 7 days (liquid, static) & \pm & ++ & ++ & ++ & ++ \\
\hline Clearing zone on MSM plate & ++ & + & - & - & - \\
\hline
\end{tabular}

Table 4 Growth of different micr oorganisms on Phe at different conditions

Notes: ++, more; +, positive; -, negative; \pm , weakly positive

\subsection{Effect of alkane on phenanthrene biodegradation}

When mixed with $\mathrm{C} 16$ or $\mathrm{C} 30$, the biodegradation percentages of Phe were 93\% and 99\% respectively (Fig. 4), indicating that $\mathrm{C} 16$ resulted in inhibition of Phe degradation to some extent, whereas Phe degradation was 
not affected by $\mathrm{C} 30$. Inhibition resulted from $\mathrm{C} 16$ was presumably due to the higher bioavailability of liquid C16 than solid Phe for the microbial consortium to access and uptake. In addition, competition for enzymes involved in oxidation or transport, and accumulation of by-products resulting in cytotoxicity, and blockage of enzyme induction should also be taken into consideration (Van Ha, et al., 2003). While there was no inhibition or synergistic interactions between Phe and C30, it might be attributed to lack of gene clusters that expressed enzymes related to degradation of long-chain C30. Although the presence of both alkane and aromatic compound-degrading genes within single strains appears to be common, the mixed culture has more potential use than pure culture to degrade mixtures due to its reducing inhibition effects. Mixed culture showed a complementary degrading action and a greater tolerance for toxic products, and intermediate products can act as substrates for other bacterial activity (Hughes, et al., 1997).

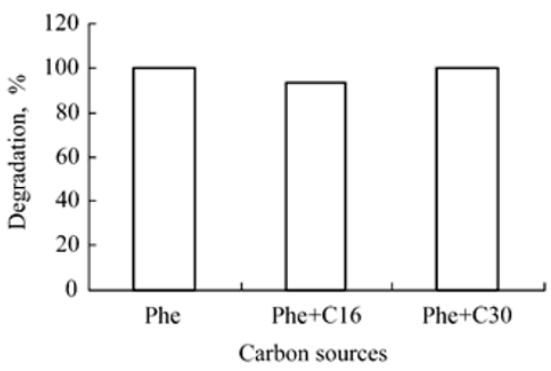

Fig. 4 Effect of alkane of different lengths on phenanthrene biodegradation

3.6 Change of components of petroleum hydrocarbons in oil sludge

After two months' degradation, a variety of aliphatic hydrocarbons in the oil sludge phase were removed. Comparison of gas chromatograms between 0 day and 60 days of degradation (Fig. 5) indicated that alkanes

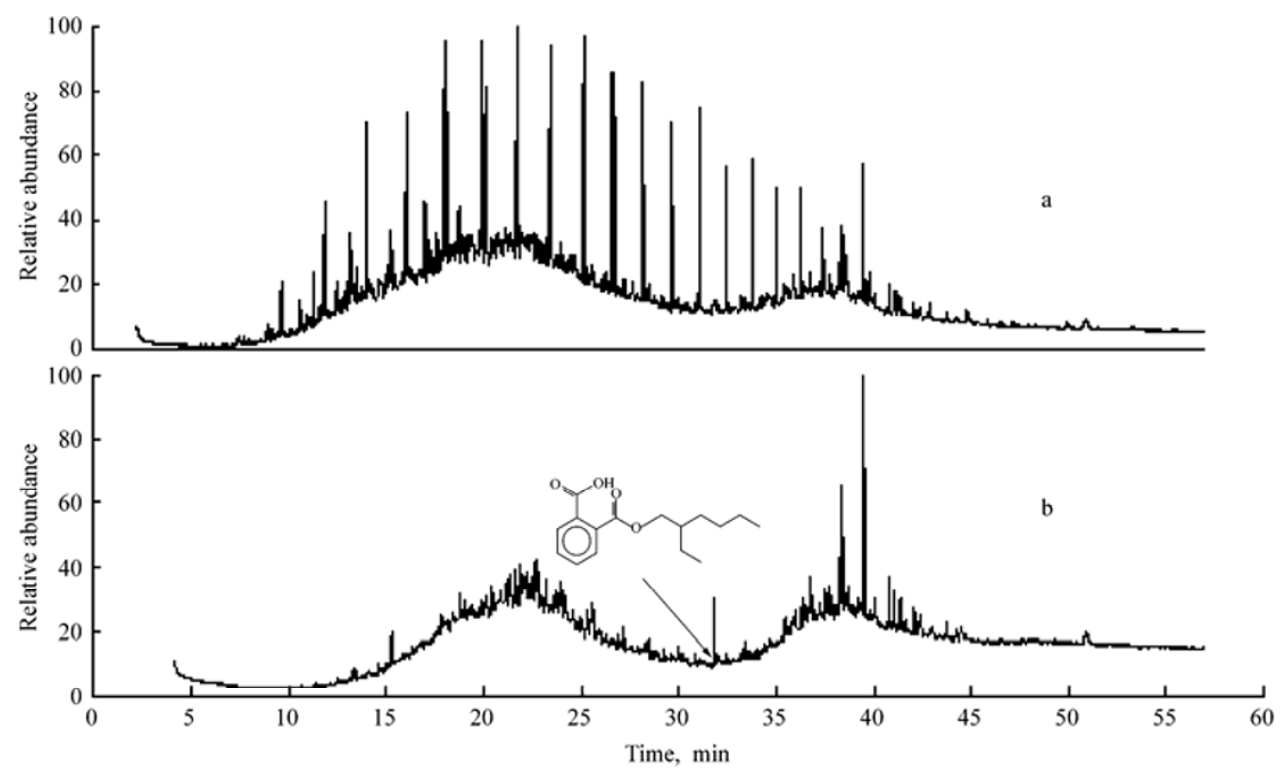

Fig. 5 Gas chromatograph of petroleum hydrocarbons extracted from oily sludge (a) Before degradation, (b) after 60 days of degradation

were almost removed and the remainder mostly belonged to heterocyclic hydrocarbons after 60 days of degradation. Meanwhile, o-phthalates were detected in extracts of 60 days' degradation, probably because of the degradation of Phe or other PAHs by the microbial consortium inoculated in oil sludge. In comparison of the content of total petroleum hydrocarbons (TPH) between composting pile samples and the control samples (data was not listed here), it was found that autochthonous microorganisms in oil sludge also played an important role in the removal of TPH. Many laboratory and field investigations showed that addition of commercial microbial cultures (bioaugmentation) did not significantly enhance the rate of oil biodegradation over that achieved by nutrient enrichment (biostimulation) of the natural microbial population (Van Ha, et al., 2003). However, other studies reported that bioaugmentation or combination of bioaugmentation and biostimulation had positive effect 
on biodegradation of PAH or TPH (Yu, et al., 2005; Bento, et al., 2005; Mishra, et al., 2001). The rate of microbial degradation of crude oil or oil waste depended on a variety of factors, including physical conditions and nature, concentration, and ratios of various structural classes of hydrocarbons, the bioavailability of the substrate, and the properties of biological system involved (Van Ha, et al., 2003), hence detailed studies are needed prior to determining a proper bioremediation method.

\section{Conclusions}

1) A microbial consortium W4, consisting of four bacterial strains: Sphingomonas cloacae, Rhizobium sp., Pseudomonas aeruginosa and Achromobacter xylosoxidans, was able to degrade solid Phe $(200 \mathrm{mg} / \mathrm{L})$ effectively via o-phthalic acid pathway and the degradation percentage was greater than $99 \%$ in liquid medium after 7 days of growth $\left(37^{\circ} \mathrm{C}, 120 \mathrm{rpm}\right)$.

2) Sphingomonas cloacae (W4-1) had a predominant role in the process of Phe degradation. Compared with W4-1, the microbial consortium W4 showed a significant improvement on phenanthrene degradation rate in either static or shaking culture, which might be attributed to the synergetic reaction of single strains.

3) When Phe was mixed with $\mathrm{C} 16$ or $\mathrm{C} 30$, the biodegradation percentage of Phe was greater than $93 \%$ and $99 \%$ respectively, indicating that $\mathrm{C} 16$ inhibited biodegradation of Phe to some extent, whereas Phe degradation was not affected by $\mathrm{C} 30$. Further, the microbial consortium W4 was also able to degrade alkanes and aromatic hydrocarbons in oily sludge.

4) The microbial consortium W4 had a promising application in bioremediation of oil-contaminated environment and could be potentially used in microbial enhanced oil recovery (MEOR).

\section{Acknowledgements}

This work was supported by a grant of "211 Project" of China University of Petroleum (Beijing) and the project sponsored by Scientific Research Foundation for the Returned Overseas Chinese Scholar, State Education Ministry. We also thank Center of Analytical Services of State Key Laboratory of Heavy Oil Processing, China University of Petroleum (Beijing) for GC-MS analysis.

\section{References}

Baboshin M. A., Baskunov B. P., Finkelstein Z. I., Golovlev E. L. and Golovleva L. A. (2005) The microbial transformation of phenanthrene and anthracene. Microbiology, 74(3), 303-309

Bento F. M., Camargo F. A. O., Okeke B. C. and Frankenberger W.
T. (2005) Comparative bioremediation of soils contaminated with diesel oil by natural attenuation, biostimulation and bioaugmentation. Bioresource, 96, 1049-1055

Boffetta P., Jourenkova N. and Gustavsson P. (1997) Cancer risk from occupational and environmental exposure to polycyclic aromatic hydrocarbons. Cancer Causes and Control, 8, 444-472

Ghazali F. M, Abdul Ra R. A. Z., Salleh A. B. and Basri M. (2004) Biodegradation of hydrocarbons in soil by microbial consortium. Int. Biodeterior. Biodegrad., 54, 61-67

Habe H. and Omori T. (2003) Genetics of polycyclic aromatic hydrocarbon metabolism in diverse aerobic bacteria. Biosci. Biotechnol. Biochem, 67, 225-243

He F., Hu W. R. and Li Y. Z. (2004) Biodegradation mechanisms and kinetics of azo dye 4BS by a microbial consortium. Chemosphere, 57: 293-301

Hughes J. B., Beckles D. M., Chandra, S. D. and Ward C. H. (1997) Utilization of bioremediation process for the treatment of PAH-contaminated sediments. Ind. Microbiol. Biotechnol., 18, 152-160

Kim Y. K., Freeman J. P., Moody J. D., Engesser K. H. and Cerniglia C. E. (2005) Effects of $\mathrm{pH}$ on the degradation of phenanthrene and pyrene by Mycobacterium vanbaalenii PYR-1. Appl. Microbiol. Biotechnol., 67, 275-285

Liu W. T. and Ritalahti K. (1996) Denaturing gradient gel electrophoresis (DGGE) protocol. ROME Lab DGGE Workshop, 5-6

Ma Y. F., Liu X. L. and Shao Z. Z. (2005) Isolation of phenanthrene-degrading bacteria and analysis of their degrading-enzyme gene. Chin. J. Appl. Environ. Biol., 11(2), 218-221 (in Chinese)

Meudec A., Dussauze J., Deslandes E. and Poupart N. (2006) Evidence for bioaccumulation of PAHs within internal shoot tissues by a halophytic plant artificially exposed to petroleum-polluted sediments. Chemosphere. (ARTICLE IN PRESS)

Mishra S., Jyot J., Kuhad R. C. and Lal B. (2001) Evaluation of inoculum addition to stimulate in situ bioremediation of oily-sludge-contaminated soil. Appl. Environ. Microbiol., 67, 1675-1681

Samamta S. K., Chakraborti A. K. and Jain R. K. (1999) Degradation of phenanthrene by different bacteria: evidence for novel transformation sequence involving the formation of 1-naphthol. Appl. Microbiol.Biotechnol., 53, 98-107

Tang L. L., Tang X. Y., Zhu Y. G., Zheng M. H. and Miao Q. L. (2005) Contamination of polycyclic aromatic hydrocarbons (PAHs) in urban soils in Beijing, Chin. Environ. Int., 31, 822-828

The Group of Bacteriology Classification of the Institute of Microbiology, Chinese Academy of Science (1978) Common methods of determinative bacteriology. Beijing: Science Press (in Chinese)

Van Ha J. D., Singh A. and Ward O. P. (2003) Recent advance in petroleum microbiology. Microbiol. Mol. Biol. Rev., 67(4), 503-549

Wang J., Xu H. K., Liu Y. Q. and Li S. J. (2006) Advance in mechanism of microbial degradation of phenanthrene. 
Microbiology, 33(5), 138-144 (in Chinese)

Wei X. F., Zhang Z. Z., Luo Y. J., Liu H. C. and Wang C. L. (2005) Application of oily sludge-treatment with excellent strains by composting. J. Petroleum. Univ. Chin., 18(4), 8-11 (in Chinese)

Xu H., Zhang J., Liu C. L. and Shao Z. Z. (2004) Isolation and identification of PAH-degradating strains and their degradation capability. Mar. Environ. Sci., 23(3), 61-64 (in Chinese)

Yu S. H., Ke L., Wong Y. S., and Tam N. F. Y. (2005) Degradation of polycyclic aromatic hydrocarbons (PAHs) by a bacterial consortium enriched from mangrove sediments. Environ. Int., 31, 149-154

Zhang X. F. and Hiroshi O. (2003) Study on isolation, identification and characteristics of polycyclic aromatic hydrocarbons degrading bacteria. Shanghai. Environ. Sci., 22(8), 544-547 (in Chinese)

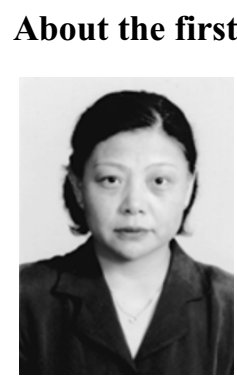

Wang Jing was born in 1954. She received her $\mathrm{PhD}$ degree from Nagoya University, Japan, in 1997 , then she had engaged in her molecular biological research as a post-doctoral fellowship of the JSPS (Japan Society for the Promotion of Science) from 1998 to 2000. She now works as an associate professor at the School of Chemical Science \& Engineering in China University of Petroleum (Beijing). Her present academic interests include biodegradation of polluted environments and microbial enhanced oil recovery.

E-mail: swhgwj898@cup.edu.cn

(Received December 9, 2006) (Edited by Zhu Xiuqin) 